\title{
UNIDAD BINARIA DEL TEMPLO MAYOR DE TENOCHTITLAN. HIPÓTESIS DE TRABAJO
}

DÚRDICA SÉgota

En un trabajo reciente, buscaba respuestas a preguntas derivadas de la enigmática presencia de Tláloc en el Templo Mayor de Tenochtitlan. ${ }^{1}$ Al principio de esta investigación había muchas dudas y una de ellas, la mayor, por cierto, era: ¿quién es Tláloc? Aquí diré solamente que el análisis de objetos arqueológicos procedentes de las últimas excavaciones del Templo Mayor y una relectura de las fuentes históricas escritas a la luz de estos descubrimientos, me llevó a definir a Tláloc como la naturaleza por excelencia, comprendida en toda su extensión y actividad.

Si bien la presencia de Tláloc en el Templo Mayor planteaba muchas preguntas, se podría decir que la de Huitzilopochtli era lógica, pues tratábase de la deidad tutelar del pueblo mexica, dios que fue su guía durante la migración, dios joven y guerrero, a veces interpretado como el sol na. ciente. $^{2}$

Sin embargo, al tratar de comprender la relación entre Tláloc y Huitzilopochtli surgieron una serie de nuevas interrogantes acerca de la identidad de ambos. Mi suposición es que tan sólo a través de su unión podemos comprender cabalmente la personalidad y la función de cada uno de ellos y también sus "tareas" conjuntas. La unidad estaba planteada por la misma concepción arquitectónica del templo, pues los santuarios de Tláloc y Huitzilopochtli se encuentran sobre un basamento único (figura 1). Compartían no sólo la estructura más grande del Recinto Sagrado, sino también el lugar más importante en lo alto de la jerarquía del panteón mexica. Dice una fuente del siglo XVI: “. . . los cuales dos dioses habían de estar siempre juntos porque los tenían por compañeros y por de tanto poder al uno como al otro". 3

1 Ségota Dútdica, Tlaloc, nature et cullure, tesis de doctorado de tetcer ciclo presentada en la École des Hautes Etudes en Sciences Sociales, Paris. Su publicación está en prepatación.

${ }^{2}$ Seler, Eduard, Gesammelte Abbandlugen zur amerikaniscben Sprach und Altertumskunde, Graz, Akademische Druck und Verlagsanstalt, 1960, VI vol,; vol. V, pp. 189 y 196; vol. II, pp. 108, 396, 397, 794, 967, 1004.6.

${ }^{3}$ Durán, Fray Diego, Historia de las Indias de Nueva España e islas de la Tierra Firme, México, Ed Porrúa, 1967, vol. I, p. 20. 
Presento aquí algunas hipótesis de trabajo acerca de esta unidad binaria. Ahora la pregunta principal es: ¿de qué manera conceptualizaba el mexica la unión de Tláloc y Huitzilopochtli?

\section{Coatépetl}

El mexica llamaba al Templo Mayor Coatépetl. ${ }^{4} \mathrm{Al}$ usar este nombre se hace una clara asociación con acontecimientos míticos del nacimiento de Huitzilopochtli y del primer enfrentamiento armado. Pero, ¿a qué obedece la presencia de Tláloc en Coatépetl, en el Templo Mayor, a lado de Huitzilopochtli?

Estudios modernos la han interpretado de diferentes maneras. Unas veces la explicación de esta extraña copresencia gira en torno del fenómeno que la antropología moderna ha nombrado la aculturación. La hipótesis que se defiende en este caso es la de una asimilación tardía de Tláloc como deidad. Es decir, el mexica durante la migración cargaba el precioso bulto de Huitzilopochtli; al llegar al Altiplano Central entró en contacto con los pueblos de la llamada alta cultura, pueblos herederos de las tradiciones toltecas. Los mexica, una vez establecidos en la región de los lagos, asimilaron muchos rasgos culturales propios de los pobladores más antiguos. Entre estos elementos adoptados fungió el culto a Tláloc. ${ }^{5}$

Anotaré aqui que, según otro autor, ${ }^{6}$ ciertos elementos que iconográficamente parecen estar relacionados con Tláloc, ya estaban presentes en los bultos sagrados que cargaban los sacerdotes mexica durante la migración.

Por otra parte, extrañaría que una deidad asimilada tardiamente con. quistara un lugar "muy principal" en la jerarquía del panteón mexica.

Otra hipótesis que se defiende es la identificación del basamento piramidal en su porción correspondiente a Tláloc como Tonacatépetl o "Cerro de los mantenimientos"? Se refiere aquí al cerro cercano a Chicomóztoc que, según la Leyenda de los Soles, Quetzalcóatl había desgranado a golpes.

${ }_{4}^{4}$ Códice Florentino, México, Secretaría de Gobernación, Archivo General de la Nación, 1979, Apéndice al libro segundo, folio $107 \mathrm{r}$

5 López-Portillo, José, Miguel León-Portilla y Eduardo Matos M., El Templo Mayor, México, Bancomer-Litógrafos Unidos, 1982. El artículo de León.Portilla, p. 64.

${ }^{6}$ Martínez Matín, Carlos, "La Cultura de los Mexicas dutante la Migración", Actas y memorias del XXXV Congreso Internacional de Americanistas, México, 1964, tomo II, p. 117.

7 Matos Moctezuma, Eduardo, Vida y muerte en el Templo Mayor, México, Ed. Océano, 1986, pp. 71.74 . 


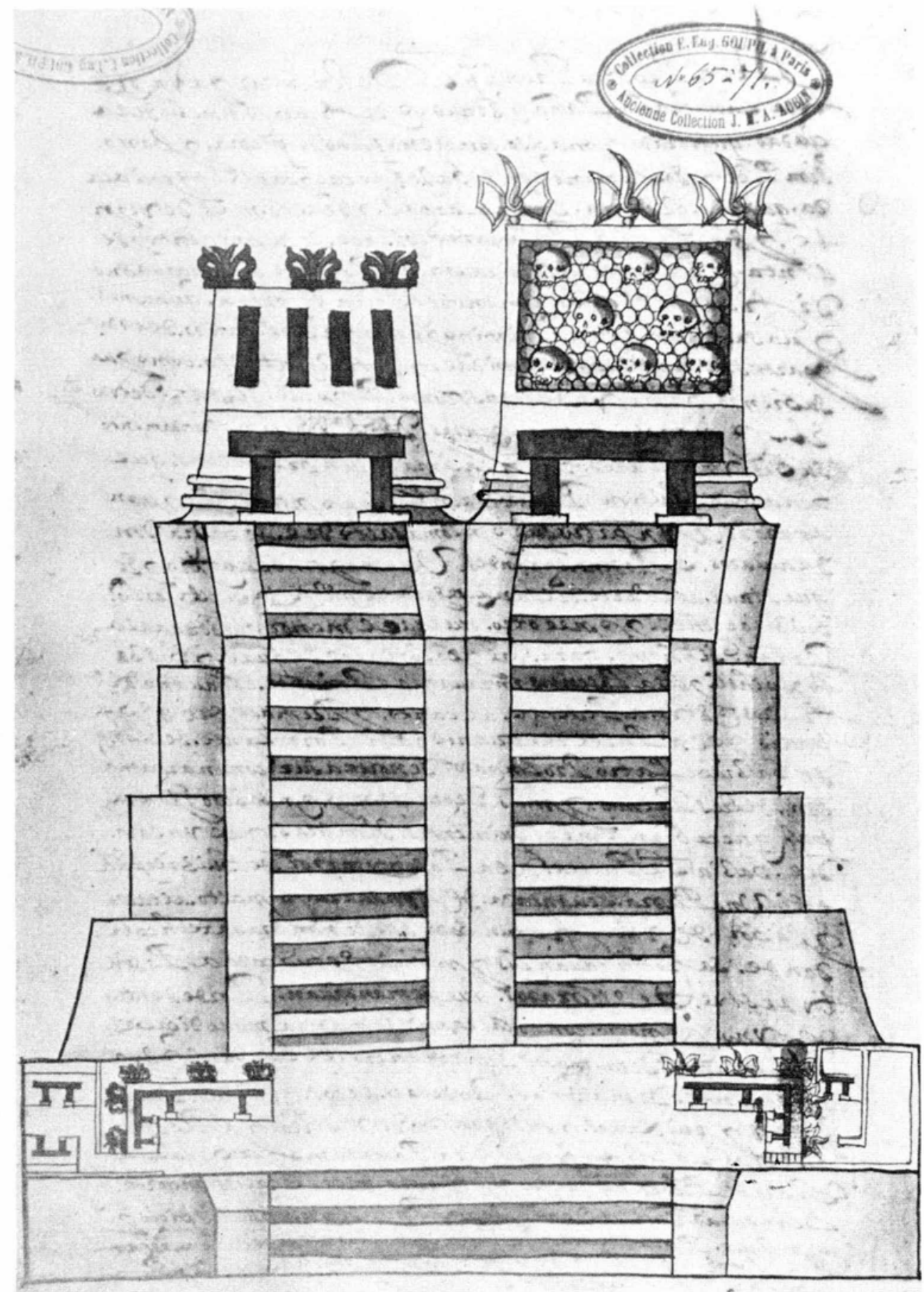

Figura 1. Templo Mayor de Tenochtitlan, Codex Ixtlilxóchitl, L. 112 v. 


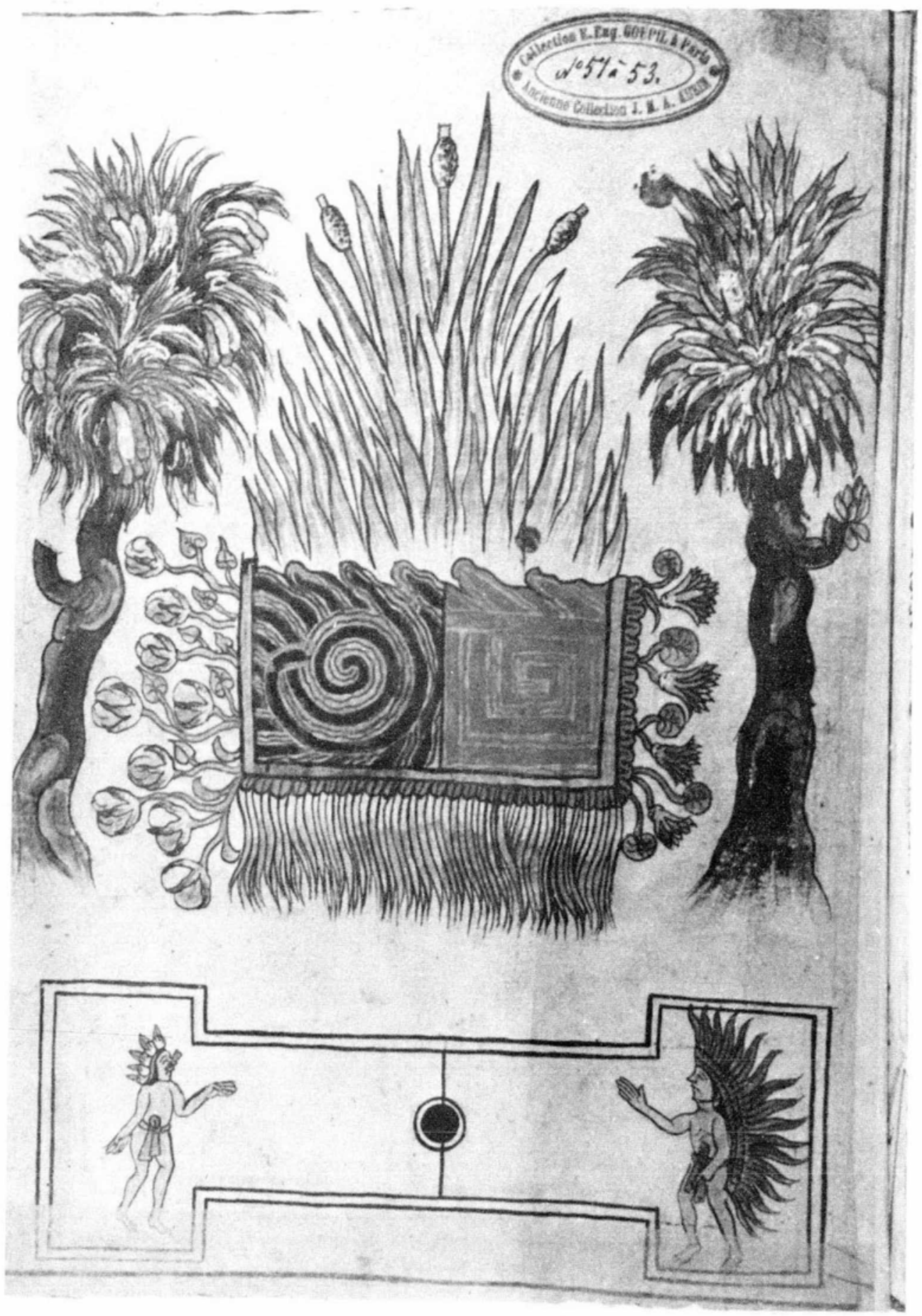

Figura 2. Historia Tolteca-Chichimeca, L. 16 v. 
De esta manera fue arrebatado el alimento a los dueños del lugar, a los tlaloque. ${ }^{8}$

Los restos arqueológicos revelan que los templos de Tláloc y Huitzilopochtli se encuentran sobre un solo basamento y que forman una sola unidad. Dicha unidad está subrayada con la distribución y el contenido de las ofrendas localizadas en las plataformas de distintos periodos; y me atrevería a afirmar que éstas, por la distribución y asociación de elementos en su interior, presentan inclusive el mismo discurso.

Ahora bien, sabemos que existen lugares que son definidos en el mito sin que por ello dejen de tener una referencia geográfica concreta. De la misma manera, existen tiempos míticos cuyo discurrir pudo corresponder alguna vez al de la historia. Éstos pudieron haber sido convertidos en lugares y tiempos "tipo", y como tales fueron incorporados en el discurso mítico. Para significar a estos lugares se puede recurrir, además de la narración misma, a una figuración bidimensional: pueden expresarse en los volúmenes de una escultura o en los espacios arquitectónicos y soluciones urbanísticas. No me refiero aquí a espacios cargados de una solidaridad mística con el territorio de los antepasados, o sea a los espacios y tiempos sagrados conceptualizados por Mircea Eliade. Sugiero el concepto de arquetipo. Este se caracteriza por ser un tipo primitivo o ideal, original, que sirve de modelo, y que como tal puede ser presentado. Las categorías espaciales, formales o cromáticas son originadas dentro del ambiente natural ideal y reciben un tratamiento correspondiente al lenguaje de las artes plásticas. Tanto el espacio del mundo o natural como el espacio artístico son "... dimensiones construidas por sus contrastes y trazos pertinentes que el espacio a su vez confirma. Lo mítico, lo imaginario, lo legendario y lo empírico se reencuentran sin contradecirse". 9

Mi hipótesis es que el espacio construido, el arquetipo de la naturaleza es el Coatépetl. Se trata de un ambiente natural que sustenta, "soporta" y vigila las primeras acciones de un dios - Huitzilopochtli-, acciones bélicas que pasarán a ser "patrimonio cultural" de los mexica, pueblo guerrero por excelencia. Tláloc, que es la naturaleza nisma, polifacético y omnipresente, está en Coatépetl, lugar que a sư vez lo presenta.

${ }^{8}$ Códice Cbimalpopoca Anales de Cuaubtitlán, Leyenda de los soles, México, UNAM, Instituto de Investigaciones Históricas, 1975, Primera Serie Prehispánica, No. 1; p. 121 .

"Zems, Abraham, "Les optiques coheréntes La peinture, est elle langage?", Revue d'Esthétique, Paris, Ed. Privat, 1967, Nouvelle Série,No. 1; p. 58. 


\section{Tláloc elige a un pueblo}

Según el mito, la adopción del pueblo mexica como "pueblo elegido" fue una decisión de Tláloc, dios de la naturaleza y de los poderes telúricos.

La Leyenda de los Soles relata que habría un pueblo poderoso en el centro de México llamado tolteca. Dominaba el altiplano central y mucho más allá de sus límites. El jefe de este pueblo, cuyo nombre era Huémac, se enfrentó un día en un juego de pelota a Tláloc. Habían apostado plumas de quetzalli y piedras preciosas llamadas chalchihuitl. Derrotado Tláloc, ofreció al hombre hojas verdes de maíz y frutos tiernos de la misma planta, los elotes, diciendo: "Son éstos nuestros chalchihuitl y nuestras plumas de quetzalli". ${ }^{10}$ Huémac consideró esto como un engaño y se negó a recibir lo ofrecido. Tláloc, como castigo por la soberbia del hombre, escondió sus tesoros por un lapso de cuatro años. En el "imperio" de Huémac reinaban la sequía, las heladas y la hambruna. Fue así como pereció el pueblo tolteca, tal y como lo había decidido Tláloc: "Ya se acabará el tolteca y se asentará el mexicano. .." ${ }^{11}$

Entre Tláloc y los mexica se estableció una alianza: el dios les otorgaría los dones de la naturaleza y ellos le ofrendarian el sacrificio de hombres. De esta manera se inició el periodo de abundancia y prosperidad del pueblo mexica, pueblo elegido por Tláloc.

Si subiéramos las gradas del Templo Mayor y volteáramos hacia la plaza, de nuestro lado derecho tendríamos el templo de Tláloc y del izquierdo el de Huitzilopochtli. Es decir, Tláloc tiene a su izquierda a Huitzilopochtli, dios principal del pueblo a quien él mismo había elegido.

Con el lado derecho están asociados los (sentidos) de bondad, de limpieza, pureza, suavidad, protección, hermosura, justicia, gracia y mucho más ... El lado izquierdo no tiene sentido peyorativo. Por el contrario, al izquierdo se le relacionaba con el corazón, es el lado del corazón... Los gobernantes supremos eran concebidos a la izquierda del dios que representaban sobre la tierra, era el sitio privilegiado para ejercer el mando en nombre de la divinidad. ${ }^{12}$

In Leyenda de los Soles, op. cit, pp. 126-127

11 Ibidem.

1:2 López Austin, Alfredo, Cuerpo bumano e ideología Las concepciones de los antiguos nabuas, México, UNAM, 1980, Serie Antropológica, 39; vol I, p. 175. 
Aquí no observamos el caso del hombre que está al lado de una divinidad, sino de dos dioses colocados en la cima del sitio más importante de México-Tenochtitlan. Están sobre un mismo basamento piramidal y tienen la misma orientación. La relación del dios de la naturaleza y de los poderes telúricos a la derecha y la deidad tribal mexica a la izquierda. Es decir, la derecha expresando la naturaleza vs. la izquierda, que representa la cultura. Era ésta una convención cultural, y el lado izquierdo pertenecía - desde luego- al pueblo que se autonombraba "elegido".

Tláloc, la fuerza vital de la naturaleza en acción constante y en peligro de que su propia actividad lo destruya; Huitzilopochtli, protector de su pueblo, tanto o más vulnerable que la naturaleza. La finalidad primordial de ambos era evitar la destrucción, como la que ya había ocurrido anteriormente, en cuatro ocasiones; es decir, preservar al mundo y al hombre, a la naturaleza y a la cultura. El "líquido precioso", la sangre del hombre sacrificado y el líquido que emana de las "venas de la tierra" vigilan y garantizan la vida.

\section{Los líquidos preciosos}

Paul Kirchhoff tenía muchas dudas acerca del carácter de Huitzilopocht1i. Dice: "Me he convencido de que es muy errónea, por muy esquemática y demasiado reducida, la caracterización de Huitzilopochtli como dios de la guerra. Lo es también, pero Huitzilopochtli es esencialmente un dios del agua". ${ }^{13}$ Su razonamiento continúa en la búsqueda de relaciones de este dios con las demás deidades, y en cada una de las fiestas del calendario ritual náhuatl. Pero no logra comprobar su hipótesis. Después de muchos análisis de vínculos entre deidades y del comportamiento de Huitzilopochtli en cada una de las festividades, ésta queda sin definición precisa. No obstante, a Kirchhoff le debemos haber puesto en tela de juicio una serie de generalidades que ya se habían vuelto lugares comunes en los estudios de la cultura mexica.

Lo que me parece de suma importancia es el acierto de Kirchhoff acerca de la "dimensión acuática" de Huitzilopochtli. Pienso que si hubiera sustituido el término "agua" por el de liquido se hubiera podido acercar mucho más a la naturaleza verdadera del dios tribal mexica.

13 Kitchhoff, Paul, Principios estructurales en el México Antiguo, México, SEP/ CIESAS, 1983. Col "Cuadernos de Casa Chata", No 91; pp. 33 y 55. 
Ahora bien, el mexica, que concibe a la gran mayoría de los fenómenos del mundo llenos de vida, encuentra el principio vital en el líquido y en el movimiento incesante de éste. Durante el "quinto sol", el líquido precioso de la naturaleza es el agua, y el líquido precioso de los hombres, la sangre; de ambas depende la vida en el mundo. Tláloc es poseedor del agua, y Huitzilopochtli "dispone" de la sangre de los hombres. Estas dos deidades preservan la vida sobre la superficie terrestre, como ya lo dije. Es justamente a través de los líquidos preciosos que se establece la relación de reciprocidad entre la naturaleza y la cultura en el interior del discurso mítico.

Por otra parte, mi hipótesis consiste en que son justamente el agua y la sangre - los líquidos preciosos, líquidos vitales- el denominador común del Templo Mayor de México-Tenochtitlan.

Cuenta el Manuscrito Tovar que cuando los mexicas llegaron al islote de la laguna central de México

...entraron por la espesura de la laguna y buscando por una parte y por la otra, tornaron a encontrar con la fuente que el día antes habían visto, y vieron que el agua que antes salía muy clara y linda, aquel día manaba muy bermeja, casi como sangre la cual se dividía en dos arro. yos, y en la división del segundo arroyo salía el agua tan azul y espesa que era cosa de espanto. . ${ }^{14}$

Como es sabido, Huitzilopochtli los había guiado, fue él quien eligió el lugar ideal para el asentamiento de su tribu; seleccionó el sitio que se autonombraba ideal ya, por la presencia simultánea y milagrosa de los dos líquidos: el rojo y el azul. Un presagio, un símbolo, una manifestación que anuncia y apoya el concepto básico que sustenta a la dualidad del pensamiento mexica en el Templo Mayor.

Es de gran belleza plástica la lámina de la Historia tolteca-chichimeca que reproduzco aquí (fig. 2) ${ }^{15}$ A esta curiosa pintura le antecede la presentación pictórica del nacimiento mítico de los pueblos nahua, lo cual, creo, no carece de una significación precisa. El "tema" central de la representación que aquí nos interesa es una especie de recipiente. El comen-

${ }_{14}$ Manuscrito Tovar, Origenes et Croyances des indiens du Mexique, Graz, Akademische Druck und Verlagsanstalt, 1972, p. 25.

${ }^{15}$ Historia tolteca-cbicbimeca, México, INAH/SEP, 1986, lámina $16 \mathrm{v}$. 
tarista se refiere a los árboles que flanquean a este extraño objeto (?). Son el iztac uexotl yhicapan y el iztac tollin ymancan. Al pie de la página hay un teotlachtli o "juego de pelota". Los personajes que lo juegan son Quauhtliztac y Apanecatl (personajes de la Historia ...). . Referente al centro del juego, anota: nauallachtli yyonocan. En cuanto al elemento central, el "recipiente", no existe anotación alguna, y es éste precisamente el que más nos interesa.

Pienso que se trata aquî de un lugar de culto. Esta hipótesis se refuerza con la presencia del juego de pelota, que era un juego ritual, y tal vez también con el tema de la lámina antecedente, el nacimiento de los macehualtin, de los "merecedores" de los dioses.

El "recipiente" mismo está dividido en dos partes iguales. Del lado derecho" se aprecia una superficie azul con espirales de líneas negras; se trata de un elemento que es identificable con facilidad: el agua. La parte izquierda del mismo "recipiente" es de color rojo y tiene un diseño anguloso, una típica greca mesoamericana. Creo que se puede interpretar, casi sin titubeos, como la sangre. (Por otra parte, recuérdese que el juego de pelota estaba asociado con el sacrificio humano).

En resumen, el extraño "recipiente" contiene -y en proporciones iguales- dos liquidos vitales, el líquido acuático y el sanguíneo. Estamos aquí en presencia de uno de los principios básicos del pensamiento religioso mexica ( $y$ tal vez nahua en general): las fuerzas vitales, de la naturaleza el uno, y del hombre, el otro. Entre ellos no existe una división tajante. Pues bien, sabemos que la naturaleza requiere del agua para reproducir el mantenimiento del hombre, pero, también según la ideología religiosa mexica, necesita de la sangre humana para reproducir sus fuerzas. El hombre igualmente, si bien la sangre es el líquido que da vida a su cuerpo, tiene presente que sin agua él y su cultura perecerían. Entre estos dos contrarios, como lo había dicho en el apartado anterior, hay una relación de reciprocidad.

La pintura de la Historia tolteca-chichimeca la considero como el arquetipo del espacio sagrado, arquetipo de un lugar de culto, una construcción espacial (y conceptual) que conocemos en el corazón del recinto sagrado de México-Tenochtitlan como Templo Mayor.

En otras palabras, planteo que el sistema figurado de Tláloc y Huitzilopochtli y el sistema iconológico agua vs. sangre (o, acuático vs. sanguineo),

* Para la relación de izquierda y derecha, utilizo el mismo criterio que expuse pata el caso del Templo Mayor 
corresponden con dos têrminos categoriales de carácter abstracto que son /naturaleza/ vs. /cultural.

Huelga subrayar que tanto la narración mítica como el lenguaje de las artes plásticas son creaciones del hombre mexica y que corresponden a sus necesidades históricas específicas. Sólo después de un estudio profundo de los valores colectivos de esta cultura - su sistema figurado y el sistema iconológico- se podrá verificar la estructura axiológica abstracta. 